\title{
POLR3A variants with striatal involvement and extrapyramidal movement disorder
}

\author{
Inga Harting ${ }^{1}$ (D) Murtadha Al-Saady ${ }^{2}$ (D) Ingeborg Krägeloh-Mann ${ }^{3}$ (D) Annette Bley $^{4}\left(\right.$ D $\cdot$ Maja Hempel $^{5}$ (D) \\ Tatjana Bierhals ${ }^{5}$ (D) Stephanie Karch $^{6}$ - Ute Moog $^{7}$ (D) Geneviève Bernard ${ }^{8}$ (D) - Richard Huntsman ${ }^{9}$ (D) \\ Rosalina M. L. van Spaendonk ${ }^{10}$ (D) - Maaike Vreeburg ${ }^{11}$ (D) - Agustí Rodríguez-Palmero ${ }^{12,13}$ (D) Aurora Pujol $^{12,14,15}$ (D) \\ Marjo S. van der Knaap ${ }^{2,16}$ (D) Petra J. W. Pouwels ${ }^{17}$ (D) Nicole I. Wolf $^{2}$ (I)
}

Received: 6 November 2019 / Accepted: 27 December 2019 / Published online: 15 January 2020

(C) The Author(s) 2020

\begin{abstract}
Biallelic variants in POLR3A cause 4H leukodystrophy, characterized by hypomyelination in combination with cerebellar and pyramidal signs and variable non-neurological manifestations. Basal ganglia are spared in $4 \mathrm{H}$ leukodystrophy, and dystonia is not prominent. Three patients with variants in POLR3A, an atypical presentation with dystonia, and MR involvement of putamen and caudate nucleus (striatum) and red nucleus have previously been reported. Genetic, clinical findings and 18 MRI scans from nine patients with homozygous or compound heterozygous $P O L R 3 A$ variants and predominant striatal changes were retrospectively reviewed in order to characterize the striatal variant of $P O L R 3 A$-associated disease. Prominent extrapyramidal involvement was the predominant clinical sign in all patients. The three youngest children were severely affected with muscle hypotonia, impaired head control, and choreic movements. Presentation of the six older patients was milder. Two brothers diagnosed with juvenile parkinsonism were homozygous for the c.1771-6C > G variant in POLR3A; the other seven either carried c. 1771-6C $>\mathrm{G}(n=1)$ or c.1771-7C $>\mathrm{G}(n=7)$ together with another variant (missense, synonymous, or intronic). Striatal T2-hyperintensity and atrophy together with involvement of the superior cerebellar peduncles were characteristic. Additional MRI findings were involvement of dentate nuclei, hila, or peridentate white matter (3, 6, and 4/9), inferior cerebellar peduncles (6/9), red nuclei (2/9), and abnormal myelination of pyramidal and visual tracts (6/9) but no frank hypomyelination. Clinical and MRI findings in patients with a striatal variant of $P O L R 3 A$-related disease are distinct from $4 \mathrm{H}$ leukodystrophy and associated with one of two intronic variants, c. $1771-6 \mathrm{C}>\mathrm{G}$ or c. $1771-7 \mathrm{C}>\mathrm{G}$, in combination with another POLR3A variant.
\end{abstract}

Keywords POLR3A · MRI · Basal ganglia · Striatum · Superior cerebellar peduncle $\cdot$ Inferior cerebellar peduncle $\cdot$ Brainstem · Hypomyelination

\section{Introduction}

RNA polymerase III (POLR3) transcribes genes encoding small, non-coding RNAs including tRNAs, 5S RNA, 7SK RNA, and U6 small nuclear RNA, which are involved in the regulation of transcription, RNA processing, and translation [1].

Electronic supplementary material The online version of this article (https://doi.org/10.1007/s10048-019-00602-4) contains supplementary material, which is available to authorized users.

Nicole I. Wolf

n.wolf@amsterdamumc.nl

Extended author information available on the last page of the article
Disease-causing variants in genes coding for POLR3 subunits were first discovered in patients with hypomyelinating leukodystrophy. They are located in POLR3A [2] and POLR3B [1, 3], which encode the largest and second largest subunits of POLR3 forming the catalytic centre of the enzyme, as well as in POLRIC [4], a gene encoding a shared POLR1 and POLR3 subunit. The resulting 4H leukodystrophy (hypomyelination, hypodontia, hypogonadotropic hypogonadism) is characterized by hypomyelination in combination with early cerebellar and subsequent pyramidal signs (usually mild) and variable non-neurological manifestations, namely dental and endocrine features as well as myopia [5]. Ataxia is the predominant clinical finding in $4 \mathrm{H}$ leukodystrophy. Dystonia is an additional, common, and initially underrecognized feature in $4 \mathrm{H}$ leukodystrophy [6], but not 
prominent at disease onset, and basal ganglia abnormalities as a potential correlate of dystonia have not been reported in $4 \mathrm{H}$ leukodystrophy. Clinical manifestations and hypomyelination in $4 \mathrm{H}$ leukodystrophy are more severe in patients with variants in POLR3A and POLRIC than in patients with variants in $P O L R 3 B[7,8]$; hypomyelination, however, is not obligatory, and manifestation without hypomyelination occurs in patients with variants in $P O L R 3 A$ or $P O L R 3 B$ [9].

During the last years, POLR3A variants without predominant ataxia have been reported: A striatal manifestation with predominant dystonia and MR involvement of putamen, caudate and red nucleus due to a homozygous founder variant in intron 13 was reported for three patients from two families with a Roma background [10]. In addition, biallelic POLR3A variants have been recognized as a cause of hereditary spastic ataxia [11, 12].

In order to characterize the striatal variant of POLR3A-related disease, we reviewed clinical, genetic, and MRI findings of nine patients with POLR3A variants and striatal changes.

\section{Patients and methods}

We retrospectively identified nine patients from eight families with biallelic POLR3A variants and striatal changes on MRI through the patient database at the Center for Childhood White Matter Disorders Amsterdam. Patients were referred to the Center for Childhood White Matter Disorders Amsterdam after identification of $P O L R 3 A$ variants, but without typical presentation for $4 \mathrm{H}$ leukodystrophy, for diagnostic evaluation. In all patients, POLR $3 A$ variants were identified by diagnostic whole exome sequencing, performed at different centres. Segregation analysis established their biallelic occurrence in all patients except patient 6 , of whom only one parent was available for testing and carried one of the patient's two variants. No other variants were found explaining the movement disorder. NIW saw patients 1, 3, 7-9; IKM saw patient 5, $\mathrm{AB}$ patient $2, \mathrm{~GB}$ and $\mathrm{RH}$ patient 6 , AR-P patient 4 . Records were reviewed for clinical presentation and are summarized in Table 1; for case histories, see supplemental material.

The patients' 18 cranial MRI scans (age at examination $0.5-29$ years, mean 9.1 years, median 4.8 years) were systematically reviewed in consensus by a pediatric neuroradiologist (IH) and pediatric neurologist (NIW). Axial T2-weighted $(\mathrm{T} 2 \mathrm{w})$ and $\mathrm{T} 1$-weighted $(\mathrm{T} 1 \mathrm{w})$ images were available for all MRI scans, sagittal T1w images for all but the follow-up MRI in patient 6 (sagittal 3D-T2w), diffusion-weighted imaging (DWI) with apparent diffusion coefficient (ADC) for at least one MRI in all patients (13/18 MRIs). MRI was assessed for presence and extent of $\mathrm{T} 2 \mathrm{w}$ grey and white matter changes, in particular for involvement of deep grey matter and brainstem tracts, and for corresponding T1-signal changes. DWI and ADC-maps were inspected for restricted diffusion, namely hyperintensity on DWI and corresponding low signal on ADC (below $60 \times 10-5 \mathrm{~mm} 2 / \mathrm{s}$ ), or increased diffusion with high signal on ADC (above 100-110 × 10-5 mm2/s, for basal ganglia and white matter, respectively [13-15]).

T2 gradient echo and susceptibility-weighted images, available for patient 9 and first MRIs of patients 1, 4, 5, and 6 (field strength 1.5 (2) or 3 Tesla(3)), were checked for hypointensities due to calcifications and/or blood degradation products; the cerebral CT scan available for patient 8 was checked for hyperdensities. Spinal MRIs were available for patients 1,5 , and 6 .

For comparison of involvement of cerebellar peduncles and/or striatum in typical $4 \mathrm{H}$ leukodystrophy, we additionally reviewed 40 MRIs of 36 patients with $4 \mathrm{H}$ leukodystrophy and imaging between 2.8 and 40 years previously published [7].

\section{Results}

\section{Patients}

All patients except patient 5 had an extrapyramidal movement disorder. Onset of symptoms varied between neonatal period (patients 1-3), infancy (patients 4-6), and early childhood (patients 7-9). Initial symptoms in the patients with neonatal presentation comprised abnormal choreic movements, restlessness, poor visual contact, failure to thrive due to swallowing difficulties, and severe global developmental delay. In the patients with infantile presentation, there were developmental delay more of motor than of cognitive development and extrapyramidal signs with dystonic posturing and poor facial expression (excepting patient 5 who had only mild ataxia). In the patients with early childhood presentation, initial motor development was normal: All patients walked without support age 12-15 months, although at least in patient 9 there were always concerns of frequent falls. In these patients, both motor function and expressive speech deteriorated in childhood with resulting severe dysarthria/anarthria and dysphagia. For a detailed description, see supplemental case reports and Table 1.

Dentition was abnormal in six of nine patients. Of six patients tested, two had mild myopia (patients 5 and 9). Only three patients (7-9) were old enough to exclude delayed puberty due to hypogonadotropic hypogonadism. Clinical, genetic, and MRI findings are summarized in Tables 1, 2, and 3 with patients sorted for age at first MRI.

\section{Genetic findings}

All patients carried at least one of two intronic variants of POLR3A, c.1771-6C $>$ G or c.1771-7C $>$ G (Table 2; Fig. 1). While the two brothers were homozygous for c.1771-6C $>$ G, all other patients were compound heterozygous: One patient 


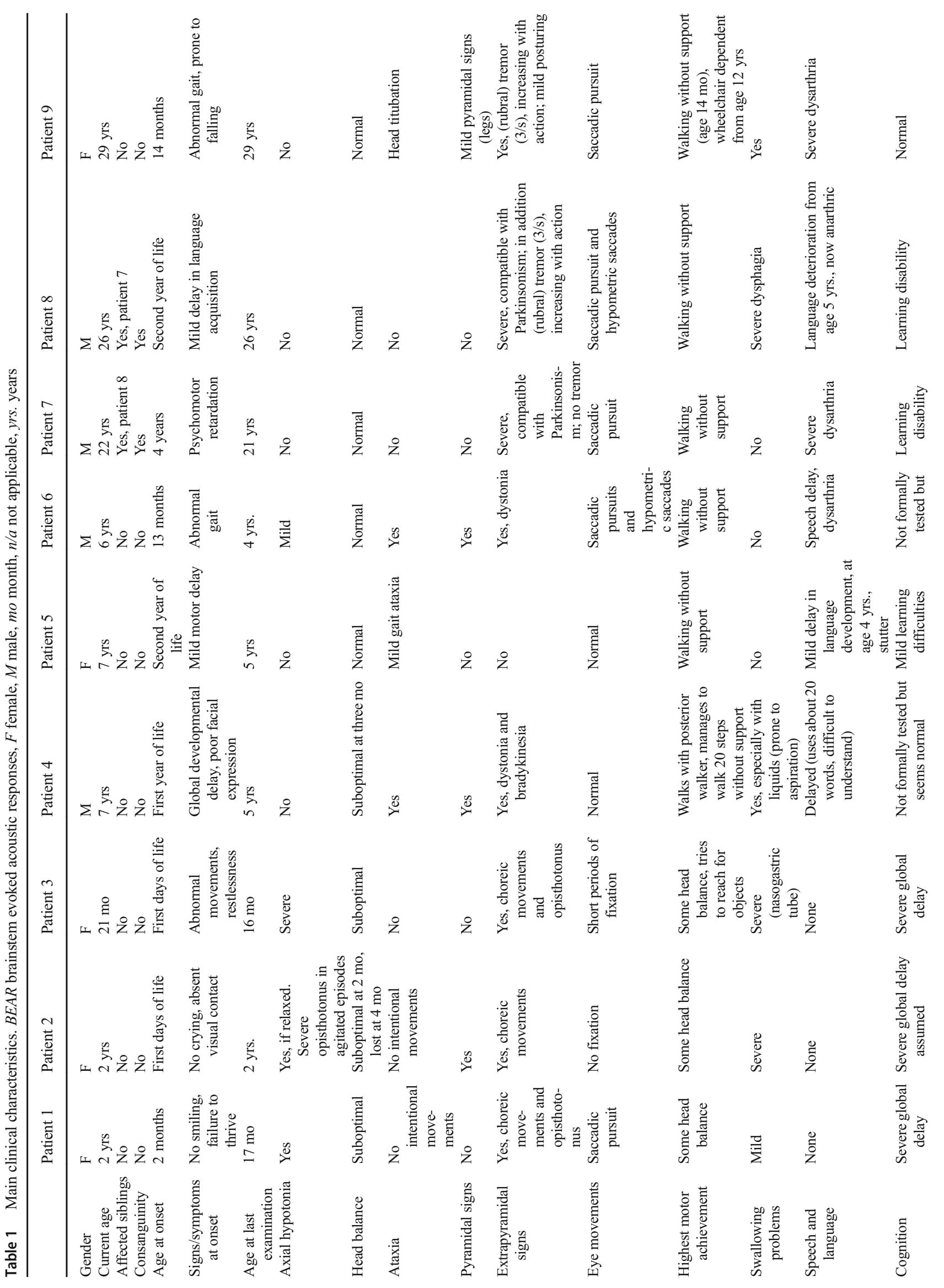




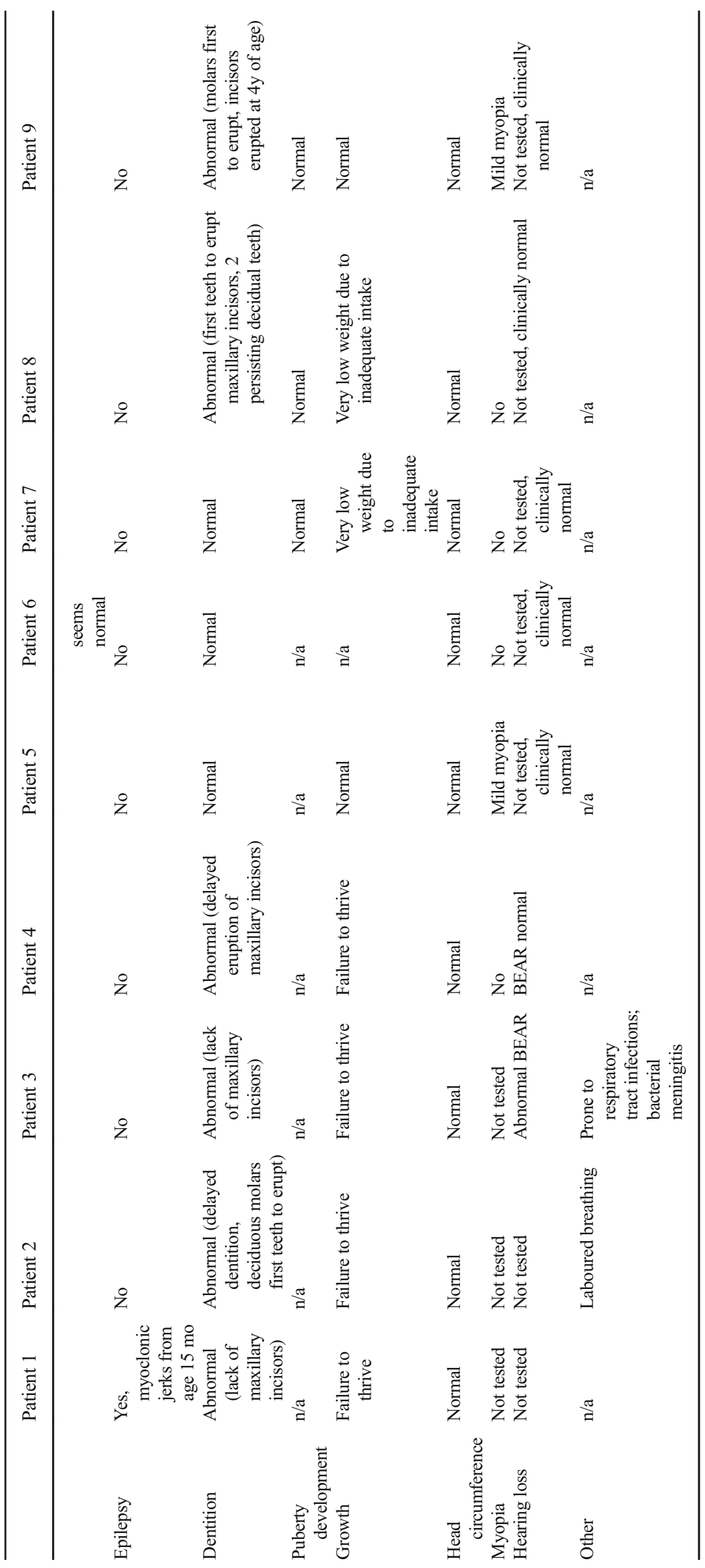


Table 2 Genetic findings. Genetic variants for all patients

\begin{tabular}{|c|c|c|}
\hline Patient & Variant 1 & Variant 2 \\
\hline 1 & c.1771-7C > G p.(Glu548_Tyr637del) / p.(Pro591Metfs*9) & c. $1048+5 \mathrm{G}>\mathrm{T}$ p. $($ Glu350Glufs $* 27)$ \\
\hline 2 & c.1771-7C > G p.(Glu548_Tyr637del) / p.(Pro591Metfs*9) & c. $4025-1 \mathrm{G}>$ A p.? \\
\hline 3 & c.1771-7C > G p.(Glu548_Tyr637del) / p.(Pro591Metfs*9) & c.2713G > A p.(Asp905Asn) \\
\hline 4 & c.1771-7C > G p.(Glu548_Tyr637del) / p.(Pro591Metfs*9) & c.3387C > A p.(Leu1129Leu) \\
\hline 5 & c.1771-7C > G p.(Glu548_Tyr637del) / p.(Pro591Metfs*9) & c.2809G > A p.(Glu937Lys) \\
\hline 6 & c.1771-7C > G p.(Glu548_Tyr637del) / p.(Pro591Metfs*9) & c.1771-6C > G p.(Pro591Metfs*9) \\
\hline $7 \& 8$ & c.1771-6C > G p.(Pro591Metfs*9) & c.1771-6C > G p.(Pro591Metfs*9) \\
\hline 9 & c. $1771-6 \mathrm{C}>\mathrm{G}$ p. $($ Pro591Metfs*9) & c. $2045 \mathrm{G}>$ A p.(Arg682Gln) \\
\hline
\end{tabular}

carried the variant c. $1771-6 \mathrm{C}>\mathrm{G}$, and six carried the variant c. 1771-7C $>\mathrm{G}$ in combination with another variant. These were an intronic variant at/close to a splice site ( $n=3$; including one with c. 1771-6C $>$ G), a synonymous variant predicted to affect splicing $(n=1)$, and missense variants $(n=3)$. The two missense variants were both located in the discontinuous cleft domain and had not yet been described in patients. The c. $2045 \mathrm{G}>\mathrm{A}$ variant (heterozygous) has been described in a patient with classic $4 \mathrm{H}$ leukodystrophy [5]. The c.1048+ $5 \mathrm{G}>\mathrm{T}$ variant in a homozygous state has been described in a patient with Wiedemann-Rautenstrauch syndrome [16] and compound heterozygous with c.1771-7C $>\mathrm{G}$ in a patient classified as spastic ataxia [12]. The c.1771-7C $>\mathrm{G}$ variant has been found in patients classified as spastic ataxia, in combination with a frameshift variant $[11,12]$. The c.1771-6C > G variant has been described in patients in homozygous form with basal ganglia involvement [10]. The c.4025-1G > A, previously not reported in literature, affects a canonical acceptor site and can be considered as a loss-of-function variant.

\section{MRI findings}

\section{Basal ganglia}

Symmetric, homogeneous, mild T2-hyperintensity and atrophy of putamen and caudate nucleus (striatum) were present in all patients (Fig. 2), with corresponding hyperintensity on ADC maps and increased ADC (range 110-120 × 10-5 mm2/ $\mathrm{s})$ in those with diffusion-weighted imaging. Among the five younger patients with first imaging until 2 years, the striatum was already T2-hyperintense and atrophic in two patients at 0.9 and 1.0 year. In the other three, the striatum was initially small or normal and had become T2-hyperintense and atrophic only by follow-up at $1.5,4.8$, and 2.9 years, respectively (patients 4, 1, and 5; Figs. 3 and 4). The four older patients imaged between 4 and 29 years all had striatal T2hyperintensity and atrophy (Table 3 ). In contrast, the striatum was normal in the 36 patients with classic $4 \mathrm{H}$ leukodystrophy re-reviewed for comparison.
The pallidum was not abnormally T2-hyperintense in our patients. In those five patients with gradient echo/susceptibility-weighted images and in the CT scan of patient 8 , there was no indication of abnormal calcification, iron deposition, or blood degradation products.

\section{Cerebellum and brainstem}

All patients had signal alterations of the superior cerebellar peduncle (SCP) in at least one MRI, involving the decussation in seven patients and reaching the red nucleus in two of these. Additional findings were involvement of the hila of the dentate nuclei, the dentate nuclei, and/or the peridentate white matter in six, three, and four patients, respectively, and of the inferior cerebellar peduncle (ICP) in five. The middle cerebellar peduncles (MCP) were involved in none. In contrast, MCP were T2-hyperintense in 29, decussation of SCP in two, and ICP was not involved in any of the 36 patients with classic $4 \mathrm{H}$ leukodystrophy re-reviewed for comparison.

T2-hyperintensity of SCP did not significantly change in patient 8 between 12 and 23 years, whereas it resolved in his brother between 13 and 19 years (Fig. 5). Similarly, T2hyperintensity of SCP, hila of dentate nuclei, peridentate white matter, and ICP clearly decreased in patient 5 between 2 and 4.8 years (Fig. 4). Conversely, infratentorial changes increased in the youngest patient between 0.5 and 1.5 years: Only the decussation of SCP was hyperintense at 0.5 years, while, at follow-up, T2-hyperintensity involved the entire course of SCP as well as the hila of the dentate nuclei, peridentate white matter, and ICP (Fig. 5). Taken together, these findings suggest that signal alteration of SCP, ICP, and dentate area may be a transient phenomenon.

\section{Supratentorial white matter}

Signal of supratentorial white matter on T2w and T1w images was normal in three of the four older patients examined between 4 and 29 years (patients 6-9), while mild T2hyperintensity of pyramidal tract in the centrum semiovale and subcortical white matter was present in patient 9. The 


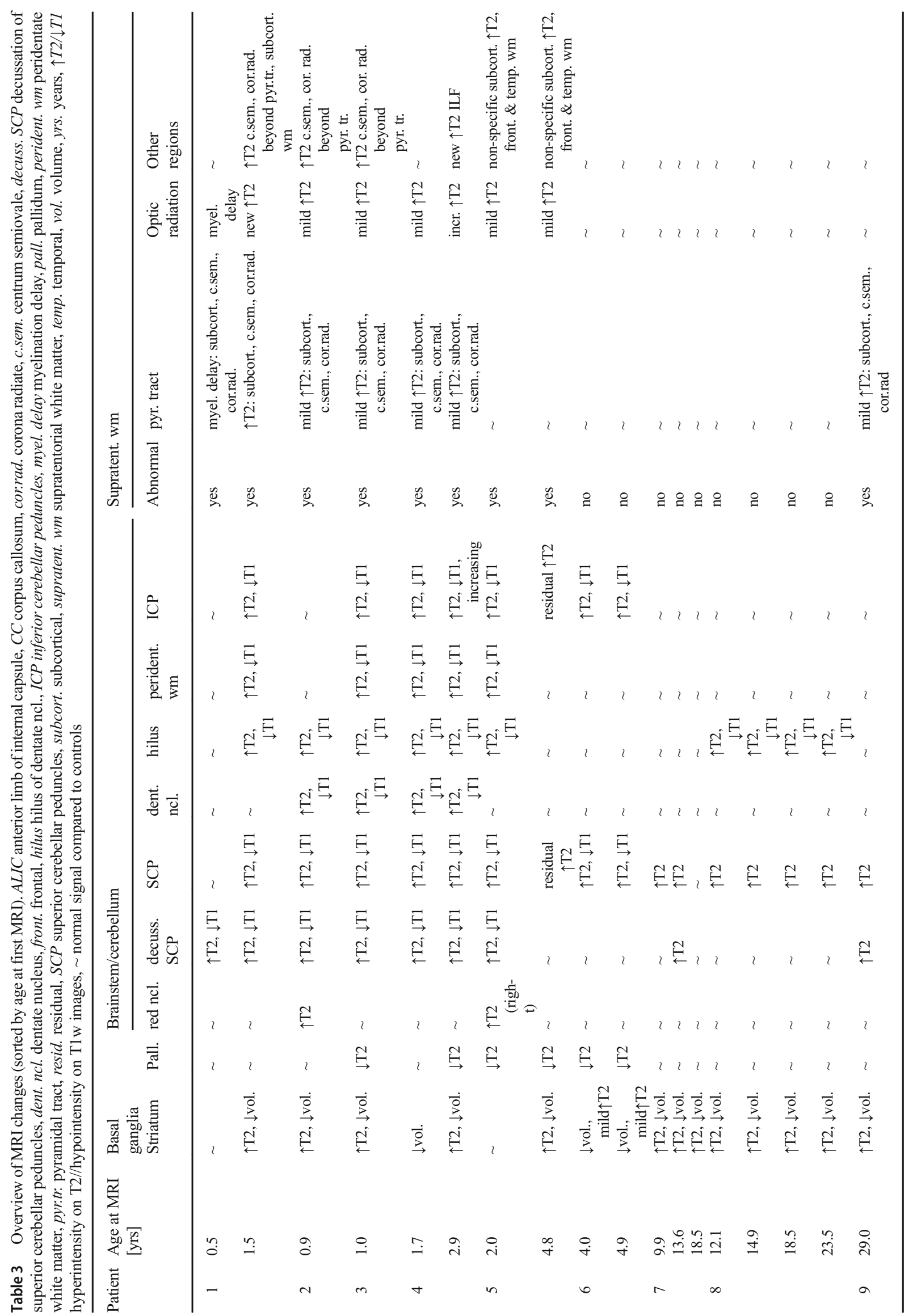




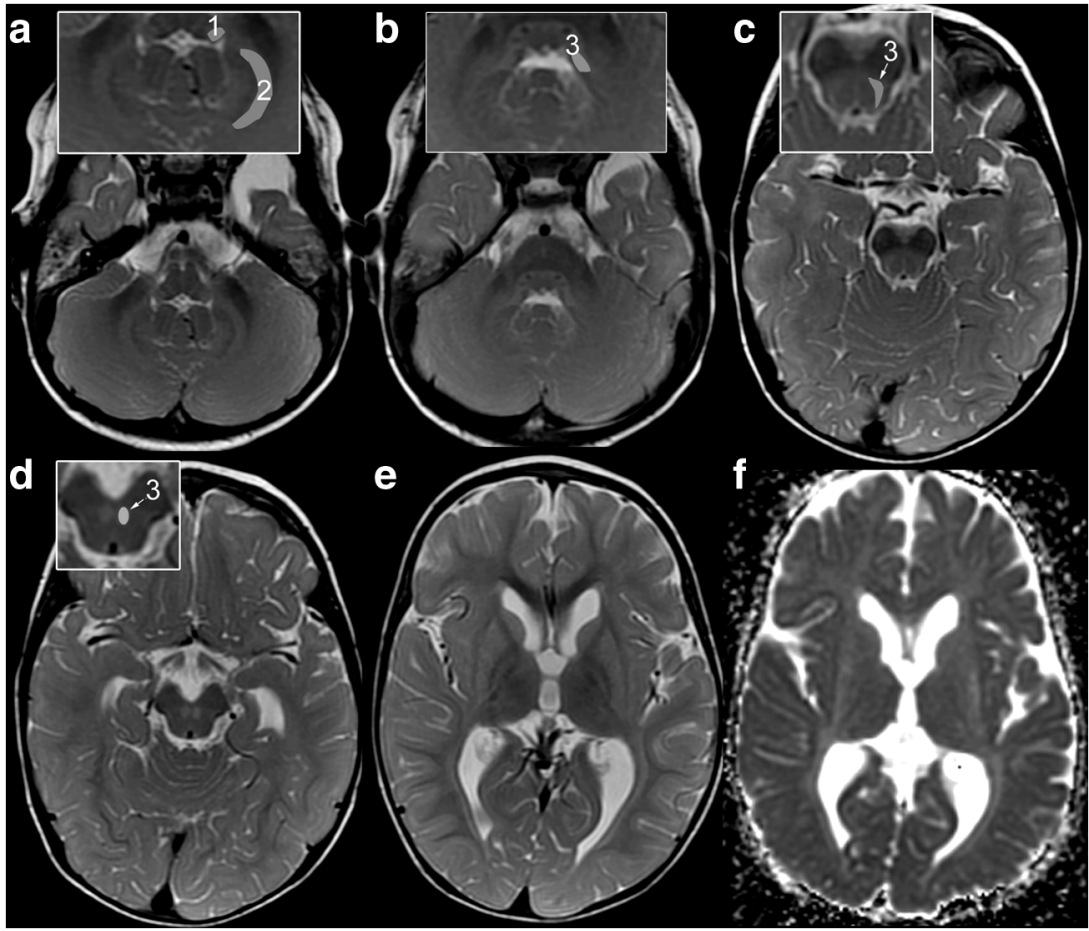

Fig. 2 Characteristic MRI pattern of striatal variant of POLR3A-related disease. MRI in patient 1 at 1.5 years demonstrates the characteristic combination of atrophic, T2-hyperintense striatum , and T2-hyperintense SCP (A-E: T2w; F: ADC-map; insets: $1=\mathrm{ICP}, 2=$ peridentate white matter, $3=\mathrm{SCP}$ ). a T2-hyperintensity of ICP (1) and peridentate white matter (2) are additional findings. b Further additional findings are T2hyperintensity of tegmentum and intraparenchymal course of trigeminal nerve. T2-hyperintensity of SCP (3, insets in B-D) is seen along its course from the cerebellum (b), dorsal mesencephalon (c) to the decussation in the anterior mesencephalon (d). e, f: Homogeneous, mild, and symmetric T2-hyperintensity of the striatum with volume loss and increased diffusion. NB the lateral medullary lamina between pallidum and putamen is commonly seen at this age due to its relative T2hyperintensity compared with pallidum and putamen; increased conspicuity is due to T2-hyperintensity of putamen (e)
Fig. 3 Small striatum and infratentorial changes at first MRI of patient 4 . At 20 months, the striatum is small (e, age-matched control image in (f) for comparison), but its signal does not exceed that of the cortex and is normal. Note involvement of ICP (a), dentate nuclei, hila, and peridentate white matter $(\mathbf{b})$, and of SCP including the decussation (b-d)

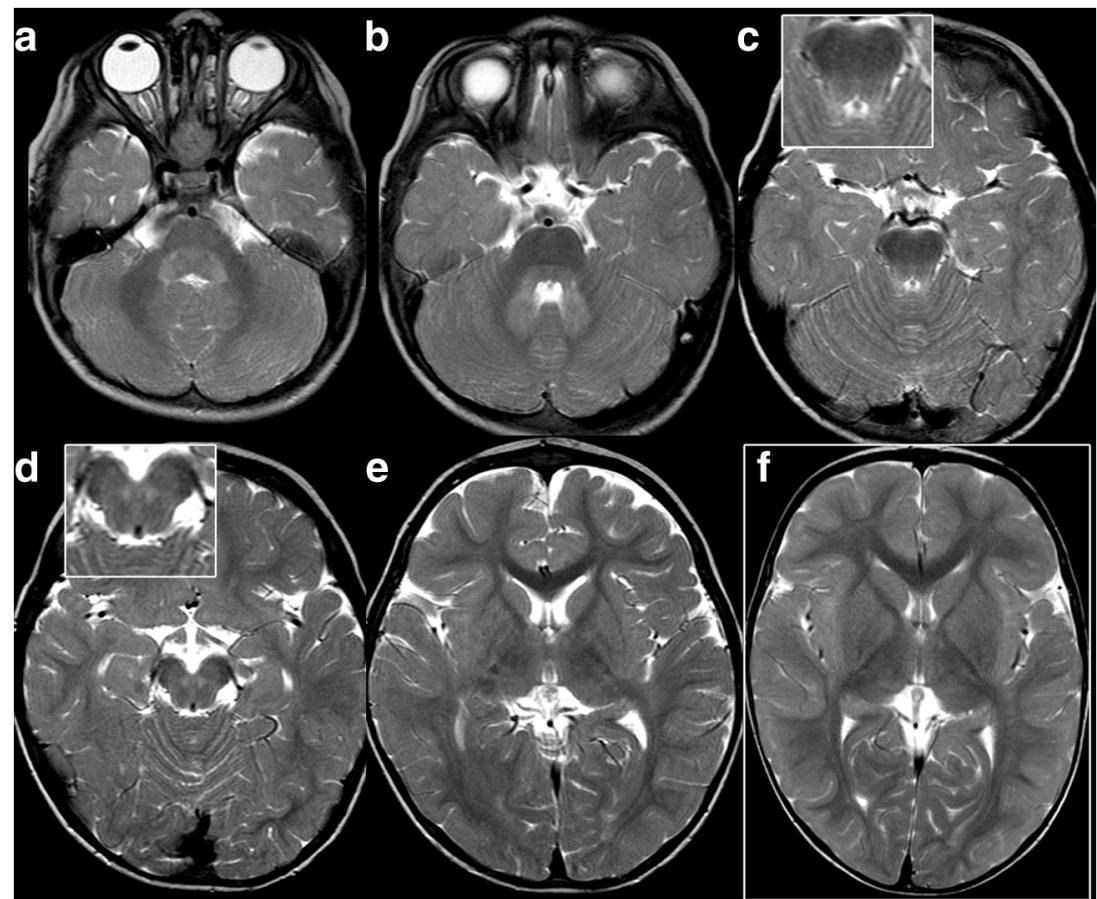


Fig. 4 Evolution of brainstem and striatal changes in patients 1 (A, B) and 5 (C, D). A, In patient 1 at 0.5 years, the decussation of SCP mildly hyperintense $\left(\mathrm{A}_{4}\right.$; inset: normal finding in agematched control) and the striatum is normal $\left(\mathrm{A}_{5}\right)$. B At 2 years ICP $\left(B_{1}\right)$, hila of dentate nuclei and peridentate white matter $\left(\mathrm{B}_{1,2}\right)$ are newly hyperintense, and $\mathrm{SCP}$ is now clearly hyperintense along its mesencephalic course $\left(B_{3}\right)$ and in the decussation $\left(\mathrm{B}_{4}\right)$. The striatum is homogeneously $\mathrm{T} 2$ -

hyperintense and atrophic $\left(\mathrm{B}_{5}\right)$. C Patient 5 also has a normal striatum at 2 years $\left(\mathrm{C}_{5}\right)$. ICP $\left(\mathrm{C}_{1}\right)$, hila of dentate nuclei, peridentate white matter $\left(\mathrm{C}_{2}\right)$ and $\operatorname{SCP}\left(\mathrm{C}_{3}\right)$, along to the red nucleus $\left(\mathrm{C}_{4}\right)$ are $\mathrm{T} 2$-hyperintense. At 4.8 years $(\mathbf{D})$, infratentorial changes $\left(D_{1-4}\right)$ are regressing whereas the striatum is newly T2-hyperintense and atrophic $\left(D_{5}\right)$

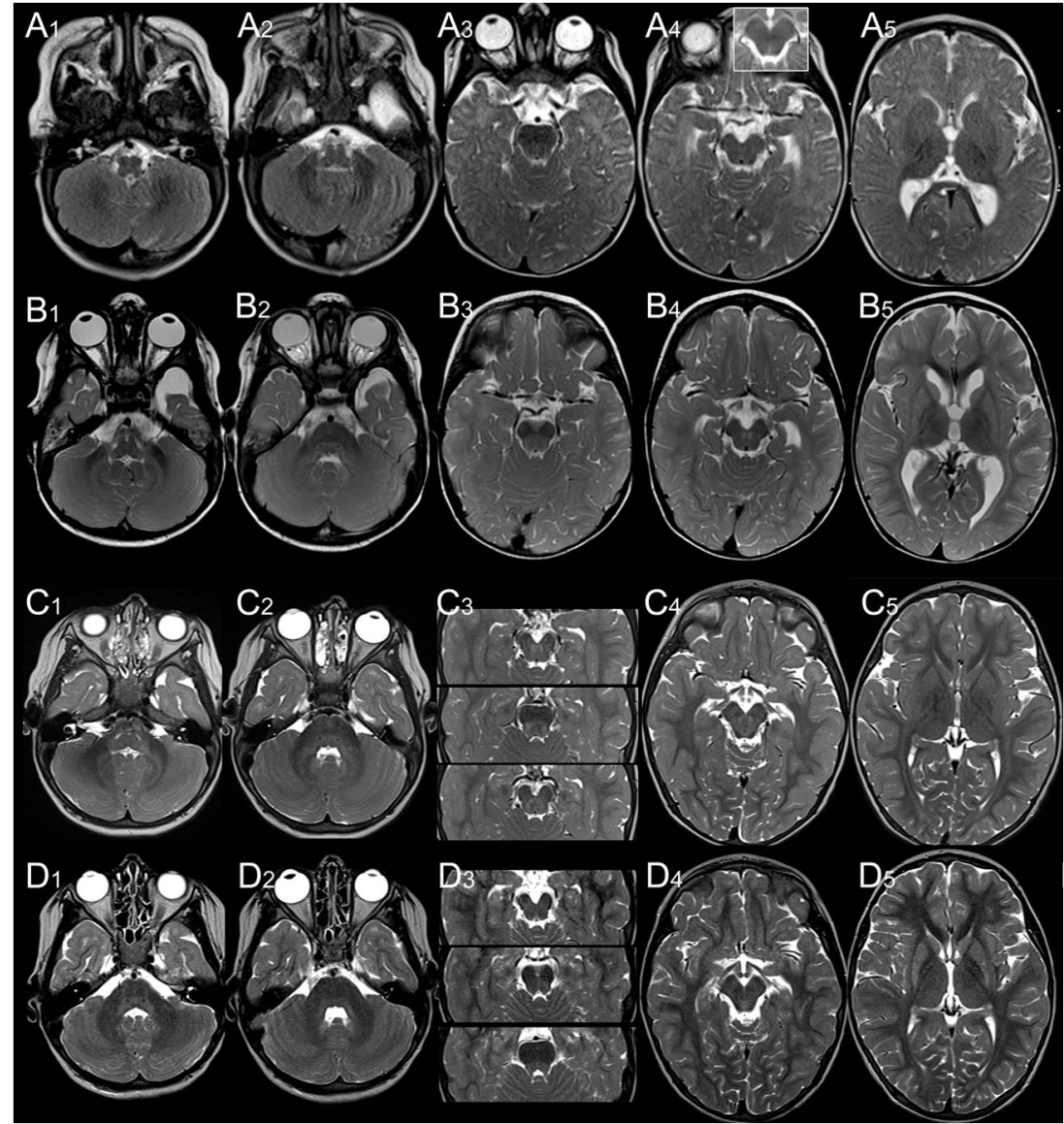

in children with $4 \mathrm{H}$ leukodystrophy and especially $P O L R 3 B$ variants, was not present.

Although our patients share variants with the spastic ataxia cohort (c.1771-7C > G; homozygous in several patients [12]), none was clinically classified as spastic ataxia. Interestingly, the original description of the patients homozygous for this variant also mentions extrapyramidal features and early onset of disease. And, while striatal changes are not mentioned, FLAIR-hyperintensity along the superior cerebellar peduncles was noted in almost all patients with the c. $1909+22 \mathrm{G}>\mathrm{A}$

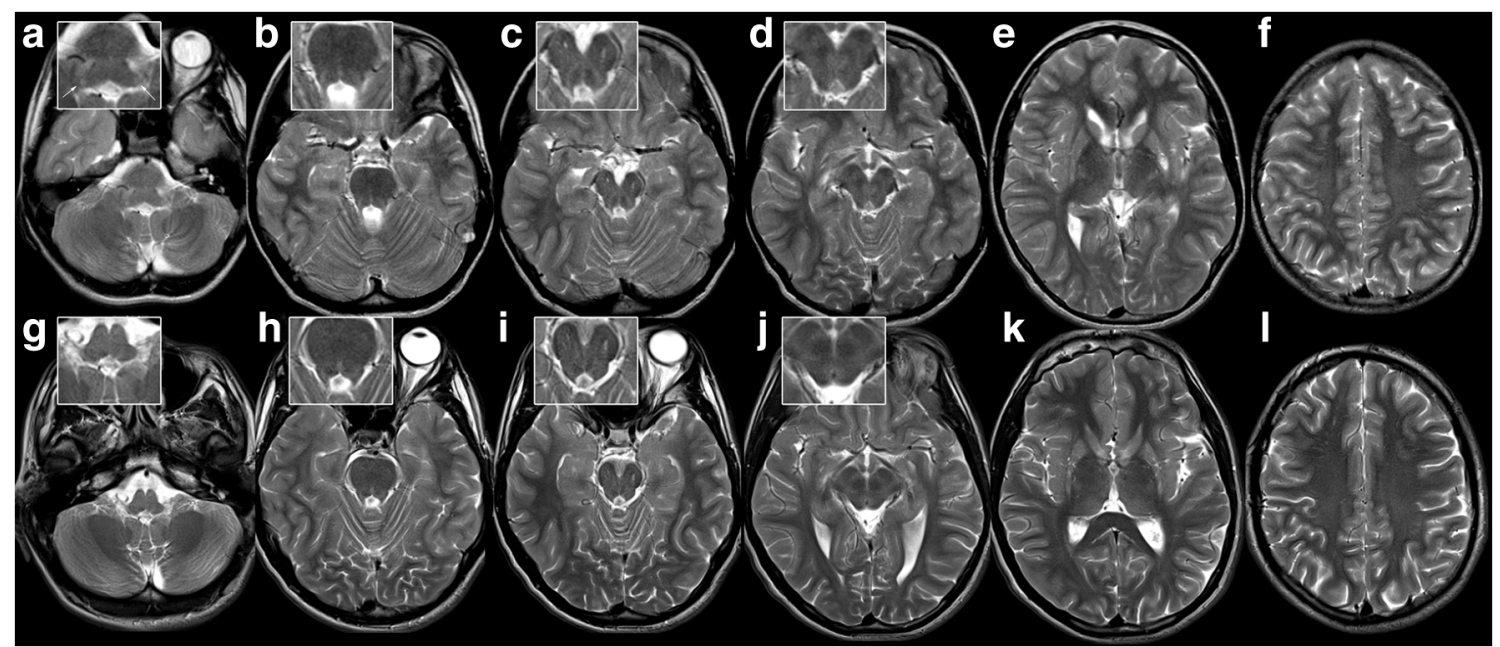

Fig. 5 Striatal injury, regressing infratentorial changes, and normal supratentorial white matter in patient 7 at 13.6 and 18.5 years. T2hyperintensity of inferior cerebellar peduncle (a, arrows in inset) and outlining the mesencephalic course of superior cerebellar peduncles (b, c; NB wide perivascular spaces in anterior mesencephalon) including their decussation (d) at 13.6 years $(\mathbf{a}-\mathbf{f})$. This has resolved by 18.5 years $(\mathbf{g}-\mathbf{l})$. The striatum is shrunken and T2-hyperintense $(\mathbf{k})$, supratentorial white matter normal (including ADC, not depicted). 
variant, but, interestingly, not in the two patients homozygous for the c.1771-7C $>\mathrm{G}$ variant [12]. They might thus also be classified as the striatal variant of $P O L R 3 A$-associated disease. One variant seen in our cohort, c. $1048+5 \mathrm{G}>\mathrm{T}$, has also been found in spastic ataxia [12] and Wiedemann-Rautenstrauch syndrome [16]. However, our patient did not have the intrauterine and marked postnatal growth retardation, lipodystrophy, or distinctive facies characteristic of the progeroid syndrome of Wiedemann-Rautenstrauch [17].

The two brothers (patients 7 and 8) with the previously described, homozygous c.1771-6C > G variant [10], had a presentation similar to that of the three initially described patients [10] with onset in childhood and severe dysarthria, hypokinesia, and rigidity. A prominent, slow resting, and acting tremor, also sometimes called rubral tremor, in addition to severe dysarthria was seen in the older brother and in patient 9, who carried the c.1771-6C $>\mathrm{G}$ variant in combination with a missense variant.

The c.1771-6C > G variant was also described in one patient said to have spastic ataxia but also with dystonia $[10,11]$, without detailed MRI information. In a publication on atypical radiological findings in $4 \mathrm{H}$ leukodystrophy, one patient also carried this variant in heterozygous form, and, in retrospect, his last MRI showed small caudate and putamen with elevated T2 signal in addition to the signal abnormalities in the posterior limb of the internal capsule, fitting with his prominent extrapyramidal symptoms [9]. Recently, a young child with the c.1771-6C > G variant in trans with a frameshift variant has been published; the MRI shows the typical basal ganglia involvement described in this work, although this was not recognized as abnormal [18].

Among the other six patients, clinical manifestation varied despite sharing the c.1771-7C > G variant on one allele and the three youngest patients (patients 1-3) were much more severely affected than patients $4-6$. The c. $1048+5 \mathrm{G}>\mathrm{T}$ variant on the second allele in one severely affected patient has been predicted to cause a frameshift with premature stop of translation [16]. It can be classified as a loss-of-function variant, similar to the variant found in patient 2 (c.4025-1G > A). The c.1771-7C > G variant itself has been shown to lead to two aberrant transcripts in addition to the normal cDNA, interpreted as activating a leaky splice site with both wildtype and aberrant transcripts [12]. Similar results were obtained for the c.1771-6C > G variant, with skipping of exon 14 and a premature termination of a part of the transcripts, with the shorter transcript being subject to nonsense-mediated decay [10].

Findings at brain imaging reflect the prominent extrapyramidal movement disorder: T2-hyperintensity and atrophy of the striatum were present in all patients, either at first imaging or on follow-up. In one case, a small striatum preceded T2-hyperintensity. A normal striatum was not seen after onset of extrapyramidal movement disorder. T2-hyperintensity was discrete and relatively inconspicuous compared with striatal injury, e.g. in glutaric aciduria type 1 or ischemia. Atrophy varied between mild and severe, e.g. in patients 1 and 7 (Figs. 2 and 5), similar to the initially described patients with striatal injury and homozygous c.1771-6C $>$ G variant [10]. Extrapyramidal signs can also develop in classic 4H leukodystrophy [6], with visually normal basal ganglia on brain MRI.

The second characteristic MRI feature was involvement of SCP, which was present in all our patients. This included the dentate nucleus and/or its hilus as the starting point of the efferent neurons of SCP in six patients and the red nucleus as a relay station in two of these. ICP was additionally involved in six patients. Involvement of SCP in patients with POLR3A variants has previously been reported for the spasticataxia cohort [12] and in four of eight atypical patients [19]. It is also depicted in a report of a patient with hypomyelination and a previously unreported homozygous variant of c. $2423 \mathrm{G}>\mathrm{A}$ in exon 18 (Fig. 2a in [20]). Involvement of the red nucleus as a relay station of SCP was reported for the three patients homozygous for the c.1771-6C > G variant [10]. The symmetric, anterior mesencephalic T2-hyperintensity also reported might rather correspond to the superior mesencephalic course of SCP than the proposed intraparenchymal course of the oculomotor nerve [10].

Changes in SCP, dentate and red nuclei, and ICP were not clearly associated with striatal injury since they preceded striatal injury in two patients and were subsequent in one. Moreover, their decrease and disappearance in two patients suggest that they are a potentially transient phenomenon. While SCP involvement in the spastic-ataxia cohort was thought to represent the structural correlate of the cerebellar manifestation [12], contribution of SCP and ICP to the clinical picture in our patients is difficult to pinpoint. This is due to the predominantly extrapyramidal movement disorder, the infrequent ataxia, and the unchanged presentation in those patients with decreasing or resolving changes, although the prominent tremor in patients 8 and 9 is certainly compatible with the involvement of the striatum and the dentate outflow tract [21].

Compared with classic $4 \mathrm{H}$ leukodystrophy, infratentorial involvement was practically inverted in patients with the striatal variant of POLR3A-related disease: While MCP was normal in the striatal variant, T2-hyperintensity of MCP has been noted in reported cases of $4 \mathrm{H}$ leukodystrophy [22-24] and was present in 29 of the 36 the previously reported patients with classic 4H leukodystrophy [7] re-reviewed for comparison. SCP was involved in only two patients with classic 
4H leukodystrophy, but in all patients with the striatal variant, ICP in none of the patients with classic $4 \mathrm{H}$ leukodystrophy and in six of nine patients with the striatal variant $P O L R 3 A$-related disease. Moreover, T2hyperintensity of cerebellar white matter with relatively T2-hypointense dentate nucleus and early cerebellar atrophy are common in $4 \mathrm{H}$ leukodystrophy [25], while cerebellar signal changes in patients with the striatal variant were restricted to dentate area, and cerebellar atrophy was absent. In addition, none of the 36 patients with classical $4 \mathrm{H}$ leukodystrophy re-reviewed for comparison had striatal T2-hyperintensity.

In 4H leukodystrophy, diffuse hypomyelination is a core finding, commonly with some myelination of the visual tract, the pyramidal tract in the posterior limb of the internal capsule, and the anterolateral thalamus [5, 25]. In contrast, myelination delay and white matter changes in our patients preferentially involved the optic radiation and pyramidal tracts, and none had frank hypomyelination. Thinning of corpus callosum, another common feature of $4 \mathrm{H}$ leukodystrophy, though somewhat less common in patients with carrying POLR3A variants [5], was only present in one of the nine patients with the striatal variant.

I

Recognition of the characteristic MRI pattern, including awareness of the potentially relatively mild T2hyperintensity and atrophy of the striatum, should trigger genetic testing for POLR3A in patients with unexplained extrapyramidal movement disorders.

Acknowledgements We thank the patients and their parents for their support and participation in this study.

Author contributions I. Harting and N.I. Wolf designed the study and wrote the initial draft of the manuscript. Diffusion-MRI was interpreted by P.J.W. Pouwels and I. Harting. MRI was otherwise analyzed by I. Harting and N.I. Wolf. I. Harting and N.I. Wolf analyzed and interpreted the data; all authors examined patients and/or collected and interpreted data. All authors revised the manuscript and approved the submission.

Funding information AP was supported by the Centre for Biomedical Research on Rare Diseases (CIBERER), the URDCat program (PERIS SLT002/16/00174), the Hesperia Foundation, 'La Marato de TV3' Foundation 345/C/2014, and the Secretariat for Universities and Research of the Ministry of Business and Knowledge of the Government of Catalonia [2017SG R1206].

\section{Compliance with ethical standards}

Disclaimer AP is a member of the Undiagnosed Diseases Program International (UDNI). The following authors are members of the European Reference Network for Rare Neurological Disorders (ERNRND), project ID 739510: I K-M, MSvdK and NIW.

Conflict of interest All authors declare no conflicts of interest in the publication of this manuscript.
Informed consent All procedures followed were in accordance with the ethical standards of the responsible committee on human experimentation (institutional and national) and with the Helsinki Declaration of 1975, as revised in 2000. The study was approved by institutional review board of VU University Medical Center (PhenoLD, 2018.300), and appropriate written informed consent obtained.

Open Access This article is licensed under a Creative Commons Attribution 4.0 International License, which permits use, sharing, adaptation, distribution and reproduction in any medium or format, as long as you give appropriate credit to the original author(s) and the source, provide a link to the Creative Commons licence, and indicate if changes were made. The images or other third party material in this article are included in the article's Creative Commons licence, unless indicated otherwise in a credit line to the material. If material is not included in the article's Creative Commons licence and your intended use is not permitted by statutory regulation or exceeds the permitted use, you will need to obtain permission directly from the copyright holder. To view a copy of this licence, visit http://creativecommons.org/licenses/by/4.0/.

\section{References}

1. Saitsu H, Osaka H, Sasaki M, Takanashi J, Hamada K, Yamashita A, Shibayama H, Shiina M, Kondo Y, Nishiyama K, Tsurusaki Y, Miyake N, Doi H, Ogata K, Inoue K, Matsumoto N (2011) Mutations in POLR3A and POLR3B encoding RNA polymerase III subunits cause an autosomal-recessive hypomyelinating leukoencephalopathy. Am J Hum Genet 89(5):644-651. https:// doi.org/10.1016/j.ajhg.2011.10.003

2. Bernard G, Chouery E, Putorti ML, Tetreault M, Takanohashi A, Carosso G, Clement I, Boespflug-Tanguy O, Rodriguez D, Delague V, Abou Ghoch J, Jalkh N, Dorboz I, Fribourg S, Teichmann M, Megarbane A, Schiffmann R, Vanderver A, Brais B (2011) Mutations of POLR3A encoding a catalytic subunit of RNA polymerase Pol III cause a recessive hypomyelinating leukodystrophy. Am J Hum Genet 89(3):415-423. https://doi.org/10.1016/j.ajhg. 2011.07.014

3. Tetreault M, Choquet K, Orcesi S, Tonduti D, Balottin U, Teichmann M, Fribourg S, Schiffmann R, Brais B, Vanderver A, Bernard G (2011) Recessive mutations in POLR3B, encoding the second largest subunit of Pol III, cause a rare hypomyelinating leukodystrophy. Am J Hum Genet 89(5):652-655. https://doi.org/ 10.1016/j.ajhg.2011.10.006

4. Thiffault I, Wolf NI, Forget D, Guerrero K, Tran LT, Choquet K, Lavallee-Adam M, Poitras C, Brais B, Yoon G, Sztriha L, Webster RI, Timmann D, van de Warrenburg BP, Seeger J, Zimmermann A, Mate A, Goizet C, Fung E, van der Knaap MS, Fribourg S, Vanderver A, Simons C, Taft RJ, Yates JR 3rd, Coulombe B, Bernard G (2015) Recessive mutations in POLR1C cause a leukodystrophy by impairing biogenesis of RNA polymerase III. Nat Commun 6:7623. https://doi.org/10.1038/ncomms 8623

5. Wolf NI, Vanderver A, van Spaendonk RM, Schiffmann R, Brais B, Bugiani M, Sistermans E, Catsman-Berrevoets C, Kros JM, Pinto PS, Pohl D, Tirupathi S, Stromme P, de Grauw T, Fribourg S, Demos M, Pizzino A, Naidu S, Guerrero K, van der Knaap MS, Bernard G (2014) Clinical spectrum of 4H leukodystrophy caused by POLR3A and POLR3B mutations. Neurology 83(21):18981905. https://doi.org/10.1212/WNL.0000000000001002

6. Al Yazidi G, Tran LT, Guerrero K, Vanderver A, Schiffmann R, Wolf NI, Chouinard S, Bernard G (2019) Dystonia in RNA polymerase III-related leukodystrophy. Mov Disord Clin Pract 6(2): 155-159. https://doi.org/10.1002/mdc3.12715 
7. Vrij-van den Bos S, Hol J, La Piana R, Harting I, Vanderver A, Barkhof F, Cayami F, van Wieringen W, Pouwels P, van der Knaap M, Bernard G, Wolf N (2017) 4H leukodystrophy: a brain MRI scoring system. Neuropediatrics 48(3):152-160. https://doi.org/ 10.1055/s-0037-1599141

8. Gauquelin L, Cayami FK, Sztriha L, Yoon G, Tran LT, Guerrero K, Hocke F, van Spaendonk RML, Fung EL, D'Arrigo S, Vasco G, Thiffault I, Niyazov DM, Person R, Lewis KS, Wassmer E, Prescott T, Fallon P, McEntagart M, Rankin J, Webster R, Philippi H, van de Warrenburg B, Timmann D, Dixit A, Searle C, Thakur N, Kruer MC, Sharma S, Vanderver A, Tonduti D, van der Knaap MS, Bertini E, Goizet C, Fribourg S, Wolf NI, Bernard G (2019) Clinical spectrum of POLR3-related leukodystrophy caused by biallelic POLR1C pathogenic variants. Neurol Genet 5(6):e369. https://doi.org/10.1212/nxg.0000000000000369

9. La Piana R, Cayami FK, Tran LT, Guerrero K, van Spaendonk R, Ounap K, Pajusalu S, Haack T, Wassmer E, Timmann D, Mierzewska H, Poll-The BT, Patel C, Cox H, Atik T, Onay H, Ozkinay F, Vanderver A, van der Knaap MS, Wolf NI, Bernard G (2016) Diffuse hypomyelination is not obligate for POLR3-related disorders. Neurology 86(17):1622-1626. https://doi.org/10.1212/ WNL.0000000000002612

10. Azmanov DN, Siira SJ, Chamova T, Kaprelyan A, Guergueltcheva V, Shearwood AJ, Liu G, Morar B, Rackham O, Bynevelt M, Grudkova M, Kamenov Z, Svechtarov V, Tournev I, Kalaydjieva L, Filipovska A (2016) Transcriptome-wide effects of a POLR3A gene mutation in patients with an unusual phenotype of striatal involvement. Hum Mol Genet 25(19):4302-4314. https://doi.org/ $10.1093 / \mathrm{hmg} / \mathrm{ddw} 263$

11. Rydning SL, Koht J, Sheng Y, Sowa P, Hjorthaug HS, Wedding IM, Erichsen AK, Hovden IA, Backe PH, Tallaksen CME, Vigeland MD, Selmer KK (2019) Biallelic POLR3A variants confirmed as a frequent cause of hereditary ataxia and spastic paraparesis. Brain 142(4):e12. https://doi.org/10.1093/brain/awz041

12. Minnerop M, Kurzwelly D, Wagner H, Soehn AS, Reichbauer J, Tao F, Rattay TW, Peitz M, Rehbach K, Giorgetti A, Pyle A, Thiele H, Altmuller J, Timmann D, Karaca I, Lennarz M, Baets J, Hengel H, Synofzik M, Atasu B, Feely S, Kennerson M, Stendel C, Lindig T, Gonzalez MA, Stirnberg R, Sturm M, Roeske S, Jung J, Bauer P, Lohmann E, Herms S, Heilmann-Heimbach S, Nicholson G, Mahanjah M, Sharkia R, Carloni P, Brustle O, Klopstock T, Mathews KD, Shy ME, de Jonghe P, Chinnery PF, Horvath R, Kohlhase J, Schmitt I, Wolf M, Greschus S, Amunts K, Maier W, Schols L, Nurnberg P, Zuchner S, Klockgether T, Ramirez A, Schule R (2017) Hypomorphic mutations in POLR3A are a frequent cause of sporadic and recessive spastic ataxia. Brain 140(6): 1561-1578. https://doi.org/10.1093/brain/awx095

13. Helenius J, Soinne L, Perkio J, Salonen O, Kangasmaki A, Kaste M, Carano RA, Aronen HJ, Tatlisumak T (2002) Diffusionweighted MR imaging in normal human brains in various age groups. AJNR Am J Neuroradiol 23(2):194-199

14. van der Voorn JP, Pouwels PJ, Hart AA, Serrarens J, Willemsen MA, Kremer HP, Barkhof F, van der Knaap MS (2006) Childhood white matter disorders: quantitative MR imaging and spectroscopy. Radiology 241(2):510-517. https://doi.org/10.1148/radiol. 2412051345

15. Li MD, Forkert ND, Kundu P, Ambler C, Lober RM, Burns TC, Barnes PD, Gibbs IC, Grant GA, Fisher PG, Cheshier SH, Campen CJ, Monje M, Yeom KW (2017) Brain perfusion and diffusion abnormalities in children treated for posterior fossa brain tumors. J Pediatr 185(173-180):e173. https://doi.org/10.1016/j.jpeds.2017. 01.019

16. Paolacci S, Li Y, Agolini E, Bellacchio E, Arboleda-Bustos CE, Carrero D, Bertola D, Al-Gazali L, Alders M, Altmuller J, Arboleda G, Beleggia F, Bruselles A, Ciolfi A, GillessenKaesbach G, Krieg T, Mohammed S, Muller C, Novelli A, Ortega J, Sandoval A, Velasco G, Yigit G, Arboleda H, Lopez-Otin C, Wollnik B, Tartaglia M, Hennekam RC (2018) Specific combinations of biallelic POLR3A variants cause WiedemannRautenstrauch syndrome. J Med Genet 55(12):837-846. https:// doi.org/10.1136/jmedgenet-2018-105528

17. Paolacci S, Bertola D, Franco J, Mohammed S, Tartaglia M, Wollnik B, Hennekam RC (2017) Wiedemann-Rautenstrauch syndrome: a phenotype analysis. Am J Med Genet A 173(7):17631772. https://doi.org/10.1002/ajmg.a.38246

18. Wu S, Bai Z, Dong X, Yang D, Chen H, Hua J, Zhou L, Lv H (2019) Novel mutations of the POLR3A gene caused POLR3related leukodystrophy in a Chinese family: a case report. BMC Pediatr 19(1):289-286. https://doi.org/10.1186/s12887-019-1656-7

19. Gauquelin L, Tetreault M, Thiffault I, Farrow E, Miller N, Yoo B, Bareke E, Yoon G, Suchowersky O, Dupre N, Tarnopolsky M, Brais B, Wolf NI, Majewski J, Rouleau GA, Gan-Or Z, Bernard G (2018) POLR3A variants in hereditary spastic paraplegia and ataxia. Brain 141(1):e1. https://doi.org/10.1093/brain/awx290

20. Tewari VV, Mehta R, Sreedhar CM, Tewari K, Mohammad A, Gupta N, Gulati S, Kabra M (2018) A novel homozygous mutation in POLR3A gene causing 4H syndrome: a case report. BMC Pediatr 18(1):126. https://doi.org/10.1186/s12887-018-1108-9

21. Choi SM (2016) Movement disorders following cerebrovascular lesions in cerebellar circuits. J Mov Disord 9(2):80-88. https:// doi.org/10.14802/jmd.16004

22. Jurkiewicz E, Dunin-Wasowicz D, Gieruszczak-Bialek D, Malczyk K, Guerrero K, Gutierrez M, Tran L, Bernard G (2017) Recessive mutations in POLR3B encoding RNA polymerase III subunit causing diffuse hypomyelination in patients with $4 \mathrm{H}$ leukodystrophy with polymicrogyria and cataracts. Clin Neuroradiol 27(2):213220. https://doi.org/10.1007/s00062-015-0472-1

23. Muthusamy K, Sudhakar SV, Yoganathan S, Thomas MM, Alexander M (2015) Hypomyelination, hypodontia, hypogonadotropic hypogonadism $(4 \mathrm{H})$ syndrome with vertebral anomalies: a novel association. J Child Neurol 30(7):937-941. https://doi.org/10.1177/0883073814541470

24. Terao Y, Saitsu H, Segawa M, Kondo Y, Sakamoto K, Matsumoto N, Tsuji S, Nomura Y (2012) Diffuse central hypomyelination presenting as $4 \mathrm{H}$ syndrome caused by compound heterozygous mutations in POLR3A encoding the catalytic subunit of polymerase III. J Neurol Sci 320(1-2):102-105. https://doi.org/10.1016/j.jns.2012. 07.005

25. Steenweg ME, Vanderver A, Blaser S, Bizzi A, de Koning TJ, Mancini GM, van Wieringen WN, Barkhof F, Wolf NI, van der Knaap MS (2010) Magnetic resonance imaging pattern recognition in hypomyelinating disorders. Brain 133(10):2971-2982. https:// doi.org/10.1093/brain/awq257

Publisher's note Springer Nature remains neutral with regard to jurisdictional claims in published maps and institutional affiliations. 


\section{Affiliations}

Inga Harting ${ }^{1}$ (D) $\cdot$ Murtadha Al-Saady ${ }^{2}$ (D) Ingeborg Krägeloh-Mann ${ }^{3}(\mathbb{D})$ Annette Bley $^{4}$ (D) Maja Hempel $^{5}$ (D) Tatjana Bierhals $^{5}$ (D) - Stephanie Karch ${ }^{6}$ (D) $\cdot{\text { Ute } \text { Moog }^{7} \text { (D) } \cdot \text { Geneviève Bernard }}^{8}$ (D) $\cdot$ Richard Huntsman $^{9}$ (D) Rosalina M. L. van Spaendonk ${ }^{10}$ (D) - Maaike Vreeburg ${ }^{11}$ (D) - Agustí Rodríguez-Palmero ${ }^{12,13}$ (D) Aurora Pujol ${ }^{12,14,15}$ (iD) Marjo S. van der Knaap ${ }^{2,16}$ (D) Petra J. W. Pouwels ${ }^{17}$ (D) Nicole I. Wolf $^{2}$ (D)

1 Department of Neuroradiology, University Hospital Heidelberg, Im Neuenheimer Feld 400, 69120 Heidelberg, Germany

2 Department of Child Neurology, Center for Childhood White Matter Diseases, Emma Children's Hospital, Vrije Universiteit, and Amsterdam Neuroscience, Amsterdam University Medical Centers, Amsterdam, The Netherlands

3 Department of Paediatric Neurology and Developmental Medicine, University Children's Hospital Tübingen, Tübingen, Germany

4 University Children's Hospital, University Medical Center Hamburg Eppendorf, Hamburg, Germany

5 Institute of Human Genetics, University Medical Center HamburgEppendorf, 20246 Hamburg, Germany

6 Division of Neuropaediatrics and Metabolic Medicine, Centre for Child and Adolescent Medicine, Clinic I, University Hospital Heidelberg, Im Neuenheimer Feld 430, 69120 Heidelberg, Germany

7 Institute of Human Genetics, Heidelberg University, Im Neuenheimer Feld 366, 69120 Heidelberg, Germany

8 Departments of Neurology and Neurosurgery, Paediatrics and Human Genetics, Department of Specialized Medicine, Division of Medical Genetics, McGill University Health Center, and Child Health and Human Development Program, Research Institute of the McGill University Health Centre, McGill University, McGill University, Montreal, Quebec, Canada
9 Division of Paediatric Neurology, University of Saskatchewan, Saskatoon, Saskatchewan, Canada

10 Department of Clinical Genetics, Vrije Universiteit, Amsterdam University Medical Centers, Amsterdam, The Netherlands

11 Department of Clinical Genetics, Maastricht University Medical Center, Maastricht, The Netherlands

12 Neurometabolic Diseases Laboratory, Bellvitge Biomedical Research Institute (IDIBELL), Hospitalet de Llobregat, Barcelona, Catalonia, Spain

13 Department of Pediatrics, Paediatric Neurology Unit, University Hospital Germans Trias i Pujol, Badalona, Barcelona, Catalonia, Spain

14 Centre for Biomedical Research on Rare Diseases (CIBERER), Institute Carlos III, Madrid, Spain

15 Catalan Institution for Research and Advanced Studies (ICREA), Barcelona, Spain

16 Department of Functional Genomics, Center for Neurogenomics and Cognitive Research, Vrije Universiteit Amsterdam, Amsterdam, The Netherlands

17 Department of Radiology and Nuclear Medicine, Vrije Universiteit, Amsterdam University Medical Centers, Amsterdam, The Netherlands 